\title{
Sensor-integrated structures in mechanical engineering: challenges and opportunities for mechanical joining processes
}

\author{
Nassr Al-Baradoni ${ }^{1}$ (D) Peter Groche ${ }^{1}$ \\ Received: 14 October 2021 / Accepted: 10 January 2022 / Published online: 29 January 2022 \\ (c) The Author(s) 2022
}

\begin{abstract}
In recent years, the trend to extend the functionality of passive metallic structures in mechanical engineering through sensor integration has emerged. This trend is driven by the growing demand for monitoring and/or control approaches. Current state of the art sensory structures and machine elements are successfully produced by integrating sensors into metallic structures using various joining techniques. However, the widespread implementation of sensory structures and machine elements has a long way to go to be achieved. For this purpose, the sensory structures must be produced not only as standardized components, but also cost-effectively with flexible configuration of the sensory characteristics and the integration of associated electronics. This paper provides an overview of the latest joining technologies for sensory structures. A discussion of the features of each joining technique will be given. In view of the importance of force/torque measurement in load-bearing structures and machine elements, an overview will be provided on the advantages and challenges of joining processes that substitute electromechanical transducers with optical non-contact measurement techniques.
\end{abstract}

Keywords Smart structures $\cdot$ Sensor-integrated structures $\cdot$ Joining processes $\cdot$ Joining by forming $\cdot$ Multi-axis force/torque sensors

\section{Introduction}

The social transformation to digitalization is accelerating. Smart components are increasingly taking over the tasks of traditional technology, and their importance is increasingly recognized. They open up additional lightweight construction potential, as well as monitor and increase the service life and safety of mobile and stationary mechanical and civil engineering structures, such as cars [1]. Sensory machine elements and load-bearing structures facilitate the digitization of existing processes and structures. They aim to extend classic machine elements with a sensory function, without any impairing for their mechanical functionality. The ongoing trend towards digitalization necessitates the adoption of smart, advanced sensor components that are able to carry out self-diagnostics or calibrations, communicate with users, predict maintenance and estimate the remaining useful life based on measured operating data and not only on operating time [2].

Nassr Al-Baradoni

al-baradoni@ptu.tu-darmstadt.de

1 Technical University of Darmstadt, Darmstadt, Germany
Currently, significant milestones have been reached in the field of sensory structures. In addition to approaches that introduce sensory structures in specific designs with limited feasibility, standardized commercial sensory machine elements are now available (e.g. piezo bolt [3]). However, the ambitious goal to transform classic structures into smart ones enacts stringent requirements on the manufacturing processes of such components, since they are mainly produced by integrating (or embedding) sensitive sensors into metallic structures. Cost-effective integration processes of flexibly configurable sensors are a prerequisite to achieving these goals. In addition, the sensory structures must be manufactured as standardized components, so that they can be implemented with almost no modification to the existing environment and based on the existing knowledge of design engineers [4].

In this paper, we will provide a comprehensive overview of the latest joining technologies for the manufacturing of sensory structures. We also demonstrate how the limitations of joining by forming for integrating multi-axis force/torque sensors can be overcome by utilizing of optical sensors on the one hand, and which approaches are potentially suitable for the position accurate integration of such sensors in mechanical structures, on the other hand. 
Firstly, the types of sensors are explained and the possible joining mechanics for creating a joint between the structure and the sensor are described. Subsequently, the investigated joining techniques are classified in accordance with DIN 8580, and their essential characteristics are highlighted. After that, the possibility of integrating multi-axis force and torque sensors into load-bearing structures and machine elements is discussed. Afterwards, the benefits and possible approaches for the integration of optical sensors into loadbearing structures will be addressed.

\section{The assembly of sensory structures}

Sensory structures refer to mechanical load-bearing structures and machine elements that, in addition to fulfilling their mechanical functions (carrying loads safely), are also capable of sensing their load conditions. Once a structure is subjected to a mechanical load, the induced change (e.g. strain or stress) extends through the joining interface to the embedded sensor. As a result, the sensor transforms this change into an electrically measurable signal, as in Fig. 1.

\subsection{Sensor types}

Depending on the level of signal processing at the sensor, sensor types can be classified into elementary sensor, integrated and smart sensor. According to Tränkler et al., elementary or basic sensor are physical transducers which convert mechanical quantities into electrically measurable quantities, such as electrical resistance, current or voltage. In an integrated sensor, the output signal is amplified and, if necessary, normalized using an active measuring circuit [5]. Smart sensors are nowadays widely used in process automation and many other fields. Their tasks include operations such as sensing, analogue-to-digital and digital-to-analogue conversion, signal sampling and quantization, and data processing [6]. They usually have a processing unit where functions can be implemented, such as the compensation of random errors, the calculation of measurement accuracy, self-calibration, the adjustment of nonlinearities to provide linear output, and self-diagnosis of errors [7]. The following figure illustrates the possible assembly of sensory structures with different types of embedded sensors.

Alongside the sensor type, the interface between sensor and host structure plays a decisive role in the resulting sensory properties of the structure.

\subsection{Joining mechanism}

The joint between the host structure and the sensor determine, how the quantity to be measured reaches the integrated sensor. The type of joint mechanism and the joint properties play a key role in the creation of sensory structures, as they determine the sensory behaviour of the created sensory structure, such as linearity or measuring resolution.

According to [8] and [9], joining mechanisms can be divided into three categories based on their physical principles: form-fit, force-fit and material-locking joints. A joint between

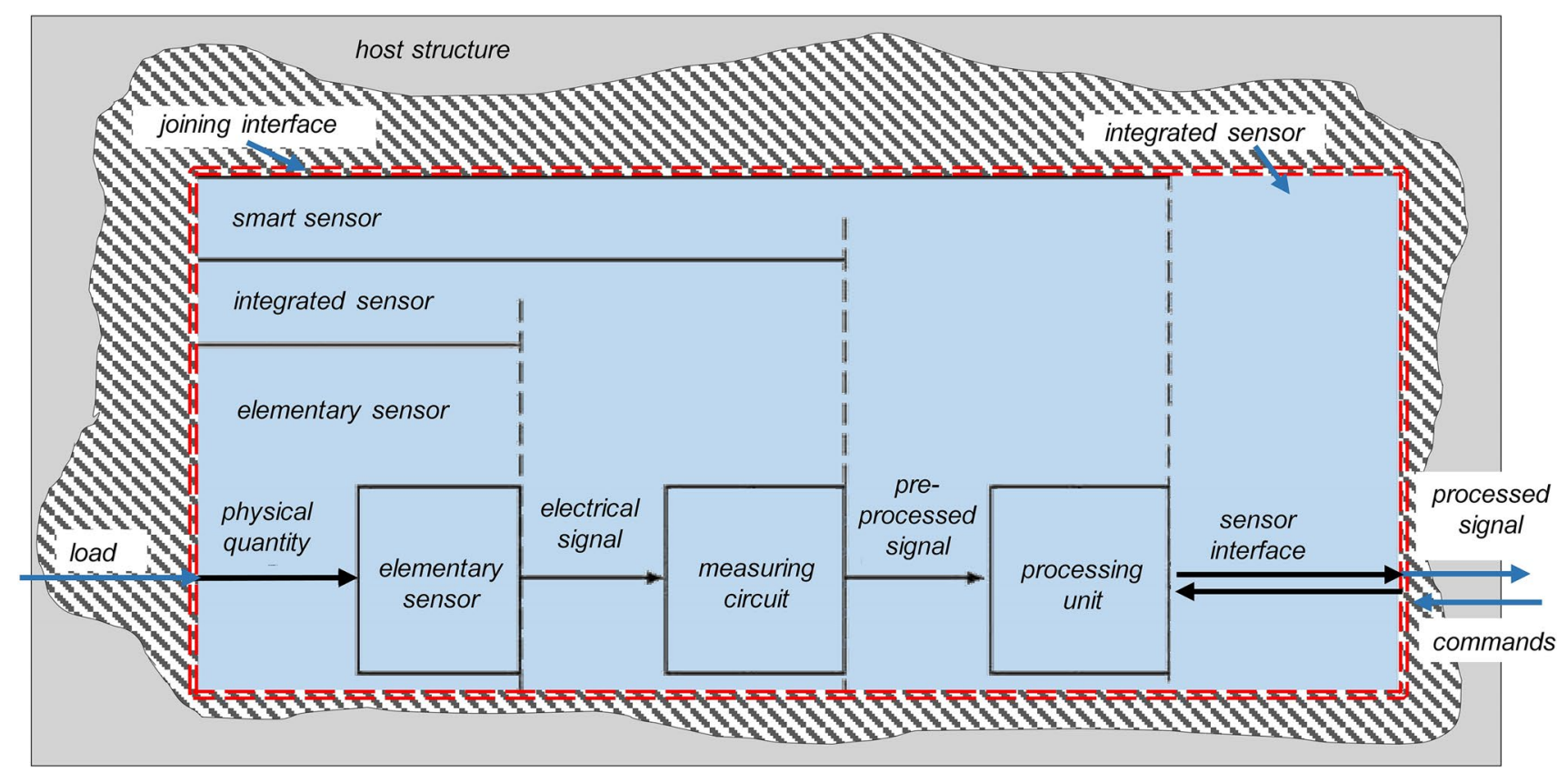

Fig. 1 Visualization of the assembly of sensory structures with different types of integrated sensors based on the degree of their signal processing at the sensor, according to [5] 


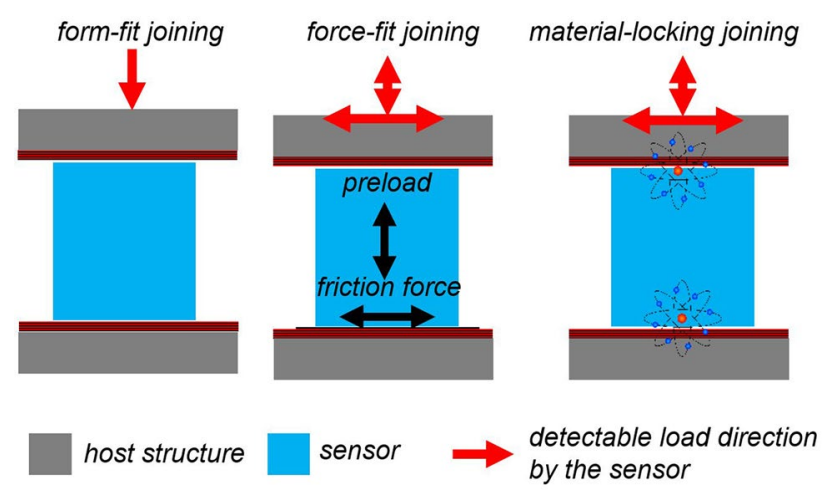

Fig. 2 Types of joining mechanisms according to [8] and [9] and the corresponding detectable load directions at the sensor

the structure and the sensor to be integrated can be created by a single or a combination of mechanisms, as shown in Fig. 2.

In the case of a form-fit joint, only compressive forces or its release can be measured by the sensor. In the case of a force-fit joint, a bidirectional load measurement is possible in all directions. However, this presupposes sufficient stiction, which is determined by the preload and the surface friction. Low preloads imply small measuring ranges, whereas high preloads can damage the sensitive sensor.

Material-locking joining relies on coherence and adhesion forces due to the exchange of valence electrons when metallic surfaces come sufficiently close to each other. They are usually achieved by welding, brazing or bonding processes [8]. These types of joint appear to be the most suitable in terms of load propagation toward the sensor due to the possible detectable load directions, without preload of the sensor. However, adhesives usually have limited processing times, costly surface preparation, long curing times and limited temperature ranges where they can be used [10]. Furthermore, a suitable bonding surface is required for optimum strength [10].

The types of sensors that can be integrated and the joining mechanism mainly depend on the joining process. The different methods for the integration of sensors in mechanical structures that are currently available are enumerated below.

\section{Joining processes}

Many studies have been conducted on the production of smart structures based on the integration of sensors into metallic structures during their processing or in a subsequent step. In the following sections, these production processes are classified into the main processing groups according to DIN 8580.

\subsection{Primary shaping}

According to DIN 8580, the primary shaping refers to the production of a solid body from an initially formless material by creating cohesion [11]. Most research on sensor integration by primary shaping processes has concentrated on embedding basic sensor elements through casting or additive manufacturing. These processes are discussed in more detail the next sections.

\subsubsection{Die casting}

According to Tiedemann et al., the die casting process is mainly used for non-ferrous materials with high flowability and low melting temperature, such as copper or aluminium. The molten metal is injected under pressure into a mold cavity. The pressure is maintained until complete solidification is reached [12]. In the field of the sensor embedding into die-cast parts, they present an approach whereby thickfilm strain gauge transducers are integrated into aluminium die casted parts using the high-pressure die-casting process (HPDC). To protect the sensing element from the high casting temperature and pressure of the HPDC machine, the thick film sensors are covered with several protective layers and with a high temperature silicone film [12], as in Fig. 3.

In a similar approach, Schwankl et al. present a method for damage-free embedding piezo patches into aluminium die casted parts utilizing hybrid support structures that protect the sensor from thermal and mechanical loads during the embedding process [13].

\subsubsection{Additive manufacturing (AM)}

Similar to die casting, additive manufacturing relies on high flexibility in the shaping of the structure and therefore attracts the integration of functional material. Research on sensor integration through additive manufacturing can be classified into two types, solid based ultrasonic AM and powder based laser engineered net shaping. These two processes are discussed in detail below.

3.1.2.1 Ultrasonic additive manufacturing In Ultrasonic AM, a metallurgical bond is created between two layers of metal foils at room temperature using ultrasonic energy [14]. Hehr et al. demonstrated that temperature-sensitive optical fibers can be integrated into components made of aluminium alloy 6061 with targeted positioning using ultrasonic additive manufacturing [15].

3.1.2.2 Laser engineered net shaping In laser engineered net shaping (LENS), a component is produced by melting metal powder that is then injected at a specific location and melted using a powerful laser beam. Upon cooling, the material solidifies [14]. To embedd optical fibers on a titanium component (e.g. a turbine blade) using laser engineered net shaping, Zou et al. used a protective cladding of cushioning material to protect the sensitive optical fiber. Applying another layer 
Fig. 3 Sensor integration using the high pressure die casting process. Thermal insulation covers the thick-film strain gauge sensor (left). Sensor after integration (right) [12]
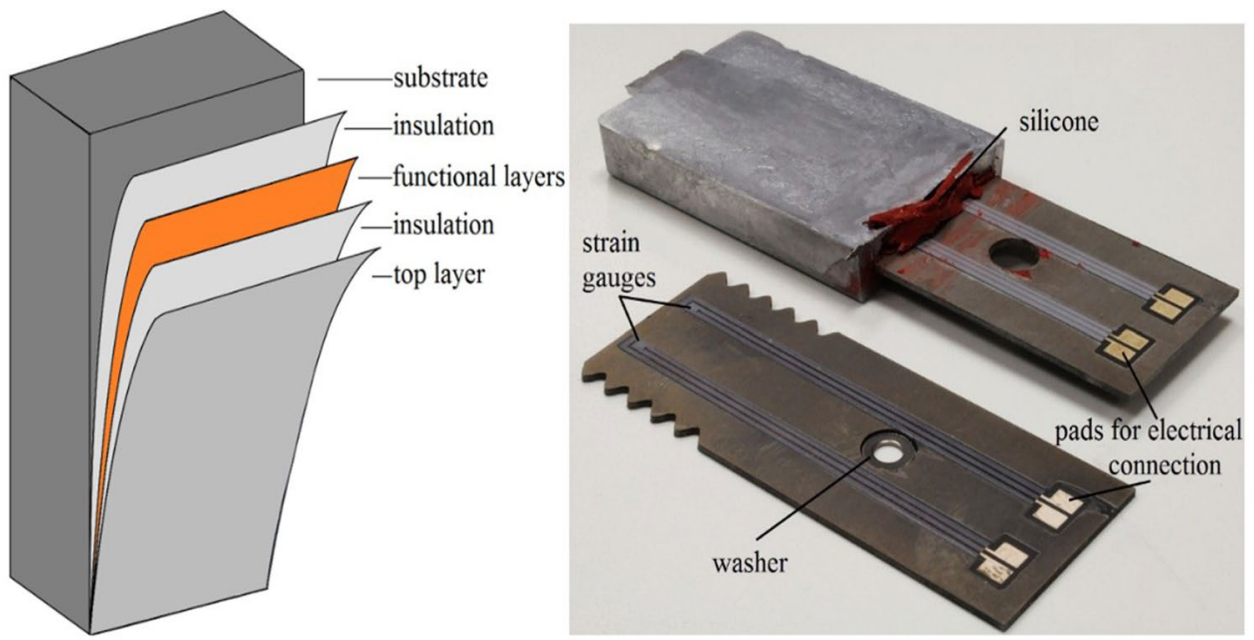

of metal to the fiber mechanically protects the fibers from the effects of high temperatures and mechanical stresses during the subsequent process of embedding through LENS [16].

\subsection{Joining}

According to DIN 8580, joining in manufacturing technology means that two or more solid bodies, the parts to be joined, each having a geometrically determined shape, are permanently connected (joined). In some joining processes, a "formless material" is also used [11]. The currently used processes for the sensor integration, namely welding and brazing, are explained in detail below.

\subsubsection{Welding (TIG)}

Tungsten arc welding, also referred to as tungsten inert gas (TIG) welding, is an arc welding process that uses a nonmelting tungsten electrode to produce the weld. In this process, the weld puddle area is protected from the atmosphere and possible contaminants by a shielding gas such as argon [17]. Grandal et al. showed how $\mathrm{Ni}$ and $\mathrm{Cu}$ coated glass fibers could be successfully embedded on a surface of tin coated steel ST-52 with a tin alloy wire [18]. In another investigation, they showed how layer-by-layer laser cladding can be applied to effectively embed fiber optic sensors. In such a laser cladding process, a material with a lower melting point than the materials to be welded is added, thereby achieving improved mechanical behaviour [19].

\subsubsection{Brazing}

In brazing, fiber Bragg grating fibers are embedded in a structure made of Inconel 600 vacuum sintering at a temperature of $900{ }^{\circ} \mathrm{C}$ using a silver-containing brazing alloy. This process fuses the brazing alloy to the metallic coating of the fiber and ensures axial and radial compression of the fibers during solidification [20].

Strain gauging fiber optic sensors used for the joining of sensors to metallic structures by welding or brazing are specially coated to withstand the high temperature of the process. Depending on the coating material and the number of layers, the fibers can withstand very high temperatures (over $1000{ }^{\circ} \mathrm{C}$ ) [21]. Figure 4 shows the concentration profile of
Fig. 4 a Percentage concentration profile of fiber core composition and $\mathbf{b}$ optical microscope image of a fiber cross-section [21].
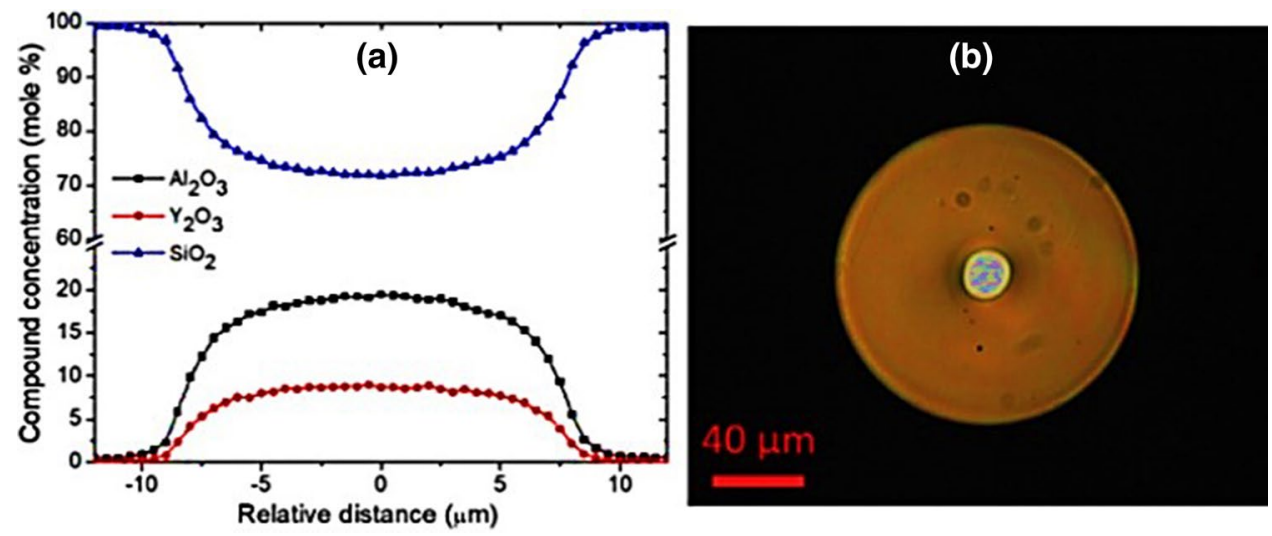
the components in the fiber core of a high temperature resistant fiber optic sensor produced by molten core fabrication as well as a cross section of such a fiber according to [21].

\subsection{Coating}

Coating means the application of thin layers on components by, for example, galvanization, painting or foil wrapping. The purpose of coating is a modification of the material properties at the surface [11]. In terms of sensory structures, Zhang presented a method of applying electric polymer-based piezo paints directly onto the surface of a host structure for fatigue crack detection. The electrical-mechanical coupling properties of the piezoelectric paint sensor allow for the production of voltage signals when it is subjected to mechanical stress [22].

\subsection{Forming}

According to DIN 8580, forming is the process of changing the shape of a component while maintaining its mass and material cohesion [11]. In particular, cold forming attracts great interest for the integration of sensors into metallic structures, since the final shaping of the structure can be done without heat treatment. The joining of sensitive sensors into metallic structures through forming is achieved by creating a force-fit or a combined force-fit and form-fit joint caused by the plastic deformation of the host structure and, eventually, an elastic deformation of the sensor. This joining technique is well known as joining by plastic deformation, as discussed in [23]. The research on creating sensory structures by means of forming techniques is presented in the following sections based on the processes used.

\subsubsection{Pressing}

For embedding micro-piezo modules into micro-structured cavities within the surface of an aluminum sheet, Schubert et al. investigated the use of pressing to join the micropiezo modules to the aluminum sheet via force fit [24] and via form- and force-fit [25]. See Fig. 5.

As can be seen in Fig. 5, as the aluminum webs are compressed by the pressing force, the gaps between the host structure and the piezo elements are filled. After the pressing force is removed, spring back of the elastic deformation of the structure occurs, and a certain amount of force-fit joint remains to preload the piezoelectric elements [25]. To ensure the setting of sufficient preload and to detect faulty joining, an approach for in-process monitoring of the preload based on the intensity of the resonance peak without overload is presented by Müller et al. [26].
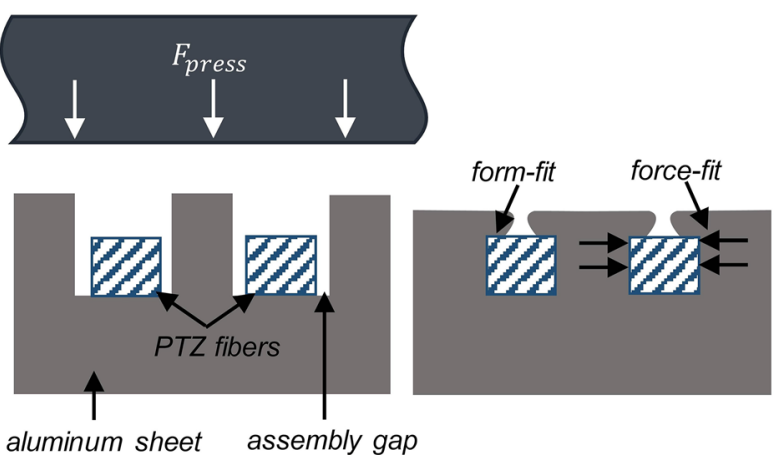

Fig. 5 Joining by forming piezo ceramic fibres in metal according to [25]: (left) assembly and joining by forming, (right) joined part

\subsubsection{Rotary swaging}

Rotary swaging is an incremental forming process for reducing the cross section of tubular or solid bar stock [27]. The sensor to be integrated is form- and force-fitted within the hollow structures during the reduction of the inner diameter. Groche et al. investigated the force- and form-fit joining of piezo [8] and strain gauge-based sensors to metallic tubes [28] and fasteners [29] by means of recess and infeed rotary swaging. The following figure shows investigated process designs and their final sensory structures.

In the process design (a) in Fig. 6, the pretension of the integrated sensor is created by an outer preform of the host structure. During the subsequent recess swaging process, the material flows along the inclined sides of the sensor, thus creating a pretension. In process design (b), an inner preform is created by means of two mandrels. The sensor is then inserted and preloaded using one of the mandrels. Through the subsequent in-feed swaging process, the material flows to the right side of the sensor to ensure sensor pretension after removal of the mandrel force [28].

Similar to the joining approach by pressing, adjusting an appropriate preload on the integrated sensor presents a huge challenge. High preloads can damage the sensors or impose a potentially high tensile load on the structure. In case of a low preload, on the other hand, the sensor and host structure will be disconnected too early under tensile loads. Figure 7 shows Krech et al.'s investigations into the influence of preload on the measuring range of axial loads on the sensory structure for the three preload cases $F_{1, \text { end }}>F_{2, \text { end }}>F_{3, \text { end }}$ [30].

As can be seen in Fig. 7, sensors with the low preload $F_{1, \text { end }}$, are not able to sense higher tensile forces due to an early lift-off of the sensor. In the case of the higher preload $F_{3, \text { end }}$, the sensor can be overloaded under relatively low compressive forces.

The integration of sensors with the required electronics enables inline measurements of the adjusted preload. To 

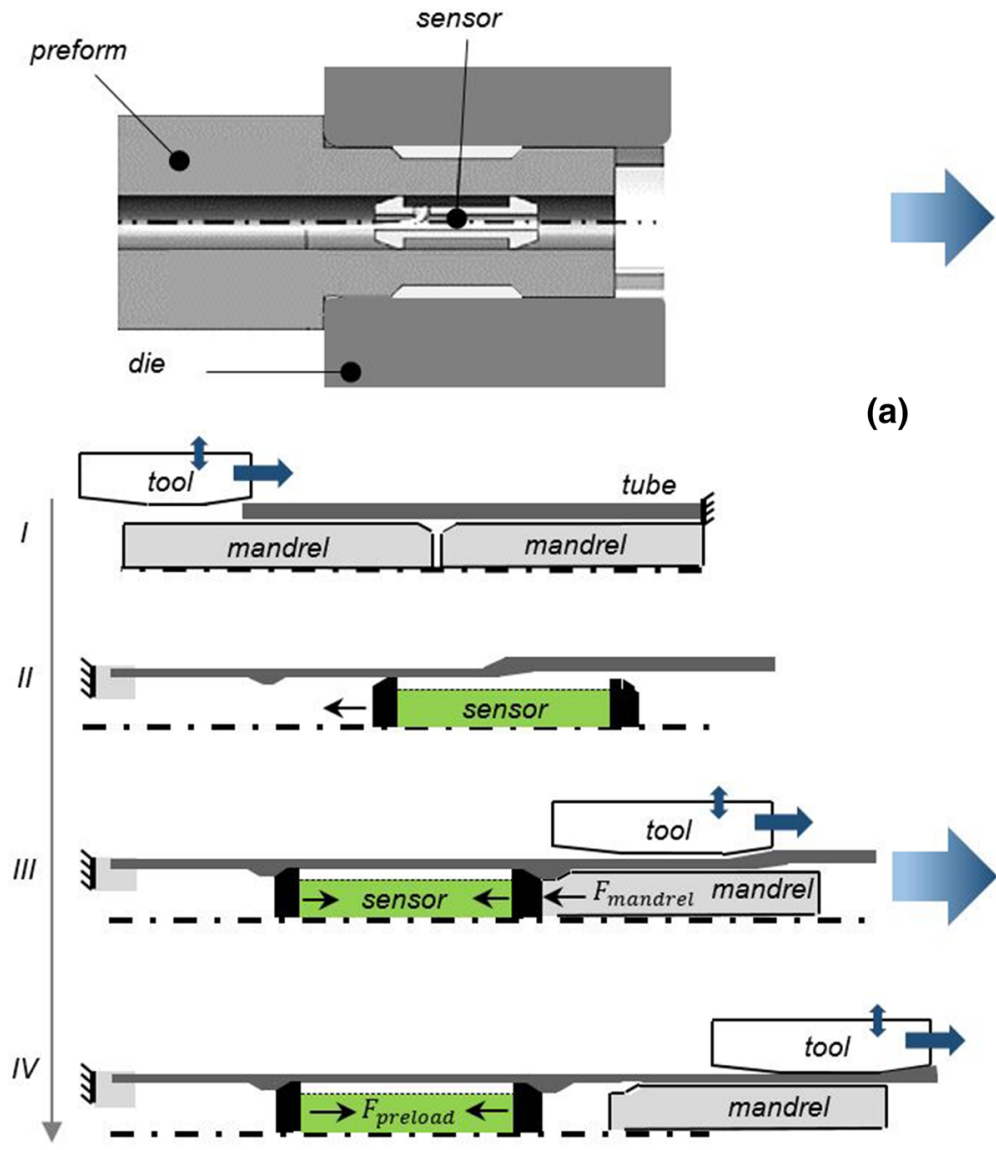

(b)

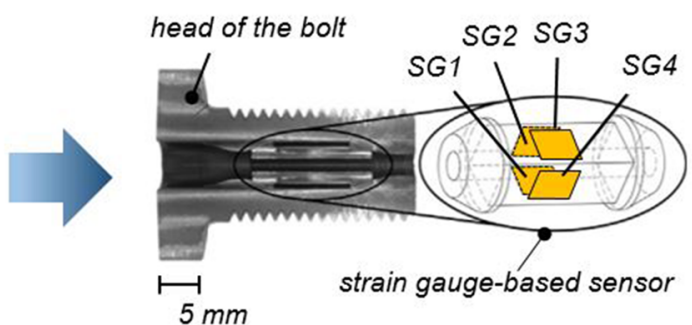

(a)

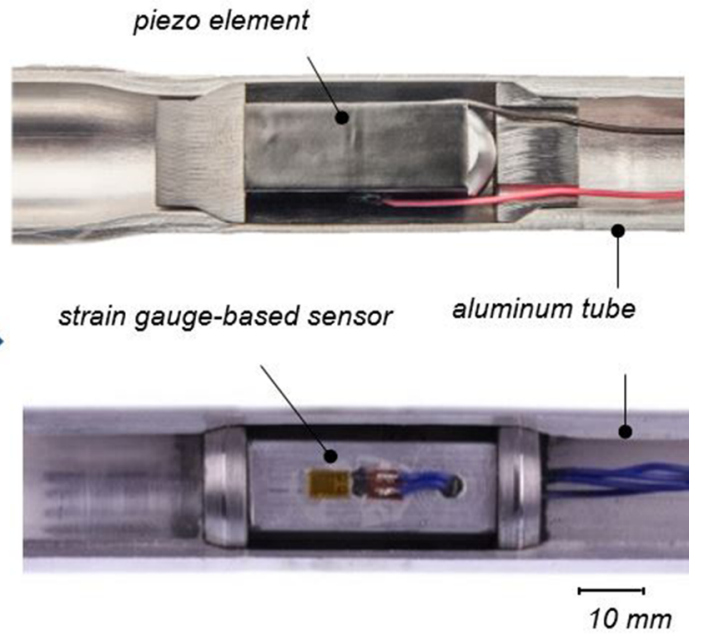

Fig. 6 Sensory structures produced by rotary swaging. Process design and final product, a for recess [29] and b for infeed rotary swaging [28]

Fig. 7 Influence of preload/ joint force on sensory behaviour. CT scan of the position of the sensor inside the structure (left), sensor behaviour under compression, and tensile load for different preload cases [30]

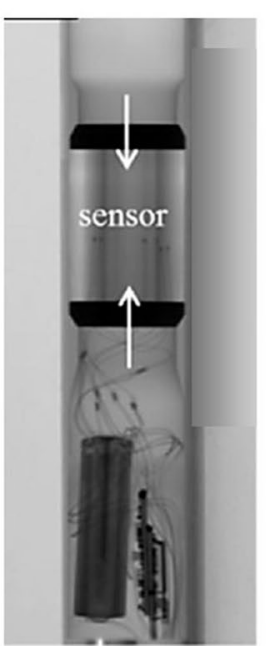

Case $1: F_{1, \text { end }}<F_{\text {ideal }}$ Case $2: F_{2, \text { end }}=F_{\text {ideal }}$ Case 3: $F_{3 \text {,end }}>F_{\text {ideal }}$

Maximum

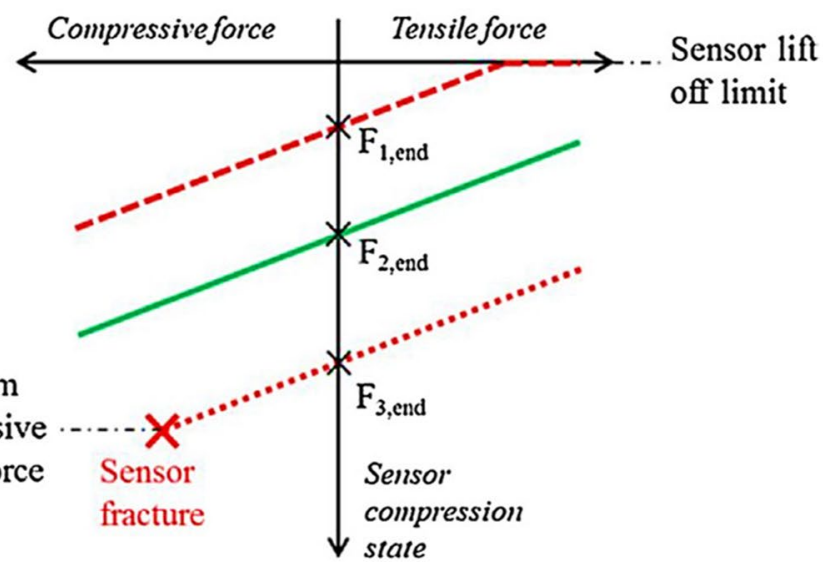


Fig. 8 Piezoceramic metal compound during joining and after forming [33]
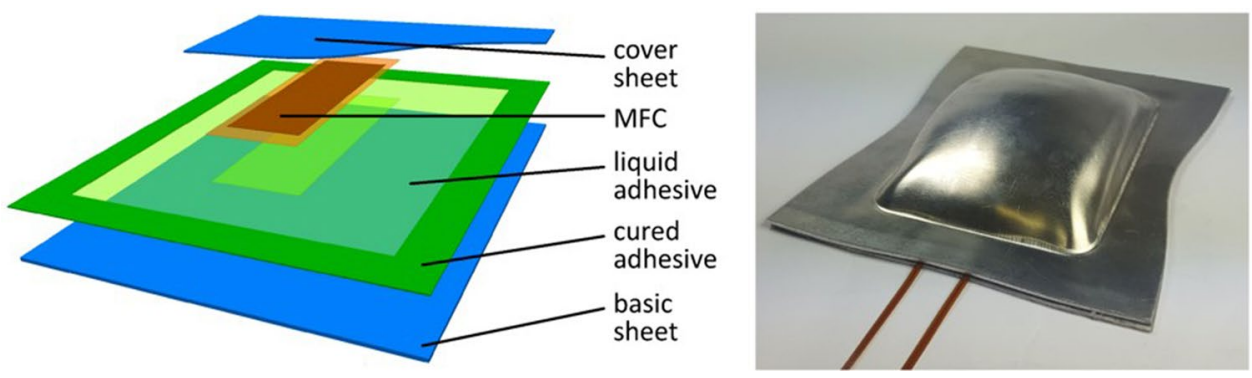

enhance the flexibility of the manufacturing process, Krech et al. introduced an approach to monitor and control the preload. As a result, sensory structures can be produced with targeted and reproducible preloads. Investigations showed a reduction of the preload deviation of about $60 \%$, despite deviating semi-finished products and process parameters [30]. In a further work, an approach to in-process calibration of the manufactured sensory structures is presented [31]. Based on the fact that the integrated sensor is able to measure the forming forces acting on the structure right after joining is achieved, in-process calibration is enabled when these forming forces are measured at a reference point in the used machine. As a result, a deviation of only $0.63 \%$ in reference to standardized calibration could be achieved [31].

\subsubsection{Formable sensory metal compound}

In other processes, the sensory materials are mainly adhesively bonded to the structure with a focus on maintaining the subsequent forming process of the component after the sensor joining process. Drossel et al. presented a process chain for the large-scale production of piezo ceramic-metalcompounds. Where the piezo module is firstly integrated into slow curing adhesive liquid, which is surrounded with fast curing adhesive. In the forming stage, the slow curing adhesive around the piezoceramic remains in a liquid condition, while the outer surrounding adhesive is cured. After forming, the compound is fully cured [32]. In another work, they investigated process chain production methods for piezoceramic compounds mainly regarding its suitability for automation. The semi-finished plane compound is then shaped in a conventional forming process, such as deep drawing. Whereby thermal treatment was applied to manipulate the curing reaction velocity [33]. Figure 8 shows the design of the compound and the finished deep-drawn part.

In a similar study, Kräusel et al. investigated the development of extrusion processes to facilitate the large-scale production of microelectromechanical systems (MEMS) which are subsequently embedded in semi-finished metal sheets by combining extrusion and rolling processes. The semifinished metal sheet is then inline coated with adhesive tape for integration into hybrid metal and fibre-reinforced plastic (FRP) structures [34]. In the context of further processability after sensor integration, Müller et al. investigated the formability of metal sheets after integration of active piezoceramic sensors. This resulted in degradation of the piezoelectric function depending on the parameters of the deep drawing process [40].

\section{The integration of multi-axis force/torque sensors}

A multi-axial force and torque sensor allows the forces and torques in all spatial directions to be sensed. This capability presents a very appealing benefit for many applications in the field of process automation or structural health monitoring. In investigations into the joining of axial force and torque measuring sensors through rotary swaging, Krech found that adjusting suitable measuring ranges for both measuring axes presents a particular challenge. In the used process design (Fig. 6b), the sensor is form and force-fitted onto the tube. The level of preload applied during the joining defines the measurement range of the axial force, as can be seen in Fig. 7. On the other hand, the preload and the friction at the joining interface determine the measuring range of the torque, since torque is transmitted to the sensor by stiction. As a result of the rotational movement of the tube during rotary swaging and the oscillating recesses of the dies, a torque is applied to the tube. Subsequent to sensor integration, this torque leads to the pre-torsion of the sensor. A targeted increase of friction at the interface, in order to increase the torque measuring range, decreases the material flow at the right side of the sensor and thus leads to a decrease of the preload [35]. Figure 9 shows the relationships between the preload and the pre-torsion as indicators of the resulting measuring ranges of axial force and torque for different friction conditions in the sensor joining interface.

As shown in Fig. 10, the effect of the different friction conditions on the sensor characteristic curve under torque load is clearly evident.

It can be seen that in case of higher friction at the joining surface between the integrated sensor and the structure, a better transmission of the torques at the joining interface is achieved. Here the sensor shows better linearity under torsional load, Fig. 10 (right). On the other hand, low friction 


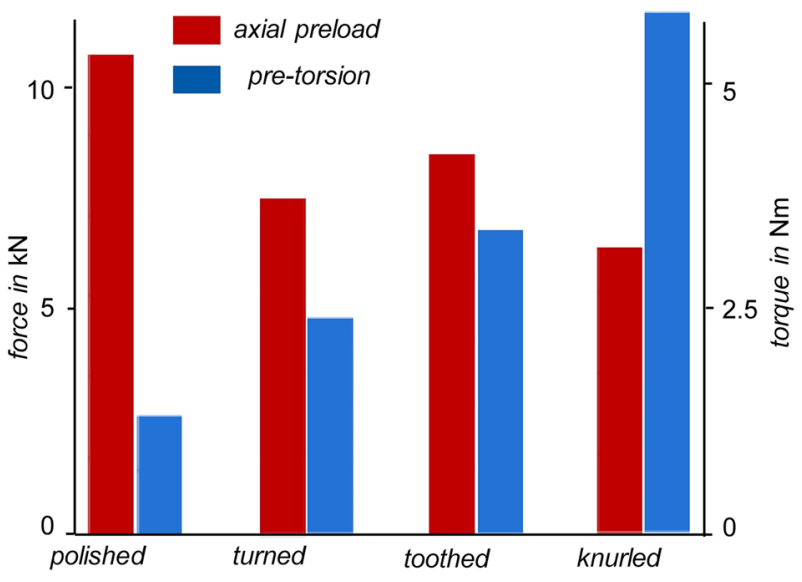

Fig. 9 The effect of increasing the friction at the contact surface of the sensor on the measuring ranges and the resulting axial preload and pre-torsion according to [35]

leads to a slippage of the sensor inside the structure under torsional load. This results in a hysteresis in the sensor signal as can be seen in Fig. 10 (left). These investigations demonstrate the challenges of integrating two-axis force-torque sensors into load-bearing structures. Studies on the manufacturing of sensory structures do not investigate the creation of multi-axis force/torque sensory structures so far. Such types of sensors are known for their stringent design requirements to ensure the anisotropic or decoupled deformation behaviour of the measuring axis (for reducing the crosstalk between the measuring axes), see also [36-38]. For such sensor designs, a form-fit joint of the sensor into the structure in all degrees of freedom seems to be promising and might ensure the unaffected functionality of the sensor after integration. However, this substantially increases both the space requirements for the necessary electronics and the production costs.

Joining techniques with more flexibility in the interface design between structure and sensor, such as casting, cannot be deployed due to their high temperatures. Consequently, higher flexibility in the manufacturing of sensory structures with multiple measuring axes must be achieved through the use of alternative sensor concepts. In a previous study, we presented an optical sensor, which allows non-contact threedimensional force/torque measurement [39]. The sensor, shown in Fig. 11 (top), consists of two parts, which are separately integrated into the host structure. Induced elastic strain, when loading the host structure leads to a relative displacement between the two sensor parts. These displacements are then captured by the built-in image sensor. Figure 11 shows a schematic design of the sensor and a CT scan image of the prototype sensor integrated into a tubular structure.

While relative in-plane displacements between plane 1 and plane 2, caused by torsional and bending loads, are detected by the occurring motion of the parallel arranged object (red light in Fig. 11), out-of-plane displacement, caused by axial loads, are detected by the occurring motion between the two mirrors. This motion results, due to the oblique arrangement of the mirrors, in a radial displacement of the twice mirrored (blue right) on the image sensor area (Fig. 11) [39]

Downstream image and data processing makes it possible to determine the displacements occurring in the two objects and assign them to the corresponding force/ torque components [39]. Figure 12 shows the validation results of this concept. In this test, a structure is uniaxially and multiaxially loaded. Beside the integrated sensor, a multiaxial strain-gauged-based reference sensor
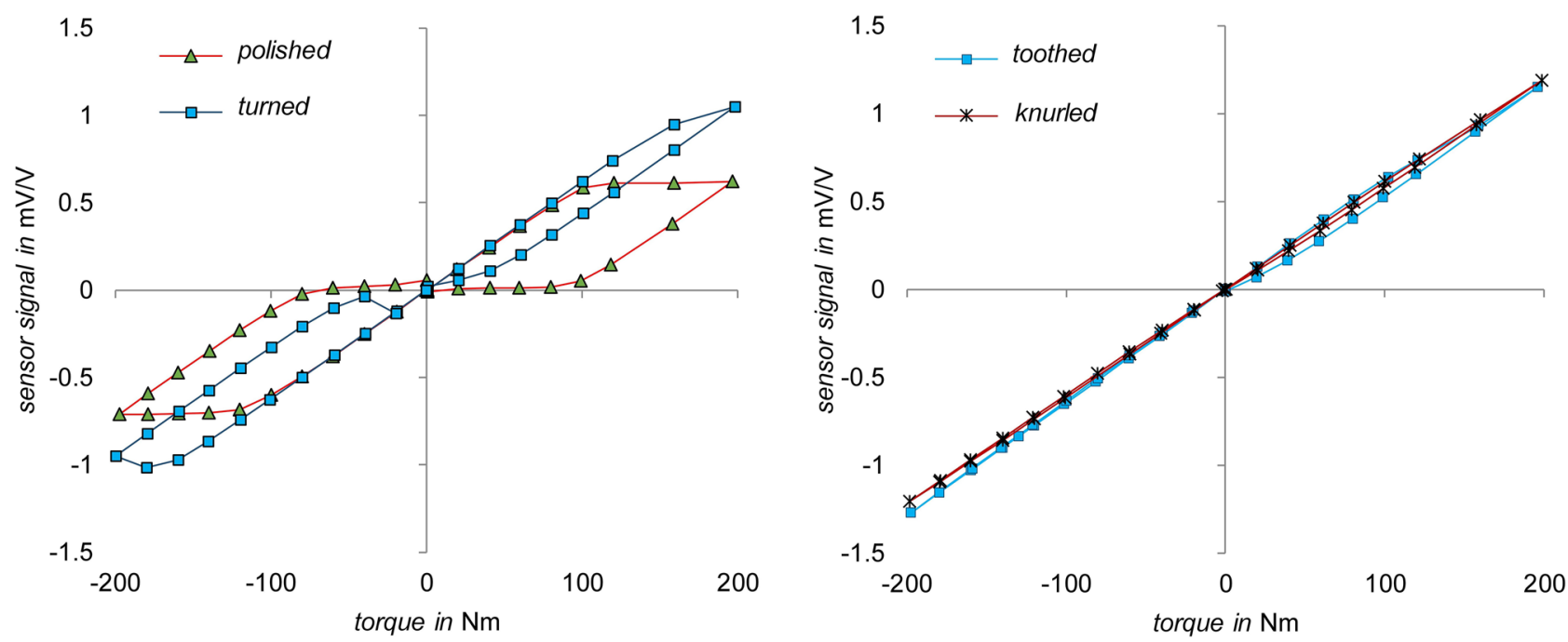

Fig. 10 Torsional load curves according to frictional conditions according to [35] 


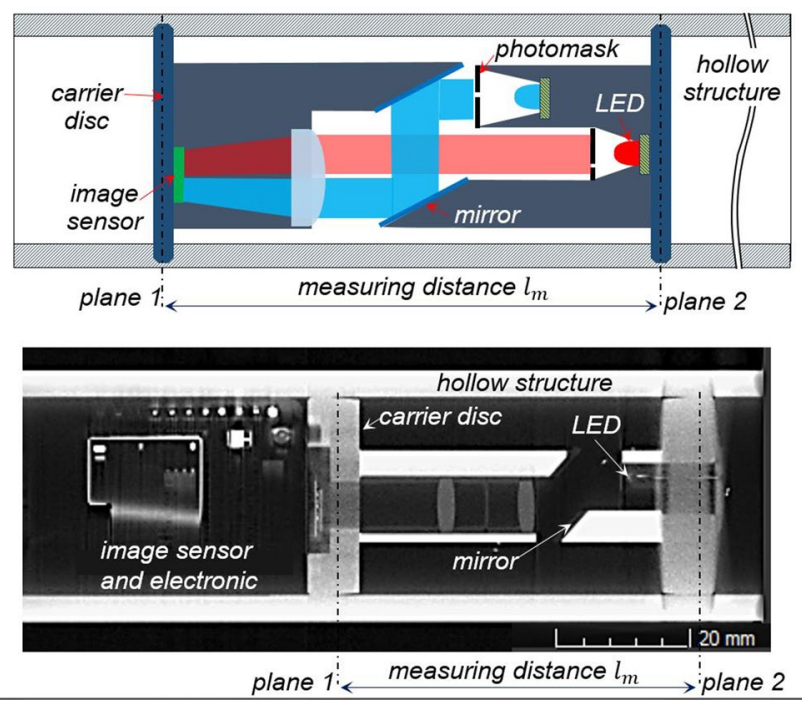

Fig. 11 Schematic design of the sensor [39] and a CT scan image of the sensor inside a tubular host structure

(K-MCS10-025, form HBM) is also deployed in the tests for validation purposes.

As can be seen in Fig. 12, the resulting displacement or twists of both reference strain-gauge-based and developed optical sensor are compared. the reference displacement and twists at the host structure (x-axis) are calculated based on the measured forces and torques at the reference sensor. The calculation procedure of the resulting displacements and twists in the optical sensor from the acquired images is described in detail in [39].

Substituting commonly used electromechanical sensors, such as strain-gauge or piezo electric sensors, with optical non-contact sensors allows direct measurement of loads on the host structure. As a result, they do not have to be transmitted via the joining interface between the integrated sensor and the host structure. However, such sensors require highly accurate positioning of the two sensor parts during the joining process. This requirement poses new challenges for joining by forming. Previously, the focus has been on the joining force for evaluating and controlling the joining process, whereas now the positioning accuracy is the subject of evaluation. This purpose requires the possibility of position manipulability of the joining partners during the joining process, without affecting the joint quality.

\section{Outlook for future works}

An approach to achieving reliable and accurately positioned joining by forming is to reduce the required joining force. On the one hand, a high joining force can impair the adjusted positioning of the joining partners. On the other hand, undesirable deformation of the discs carrying the optical elements can occur. Possible ways to achieve this include easily deformable areas on the

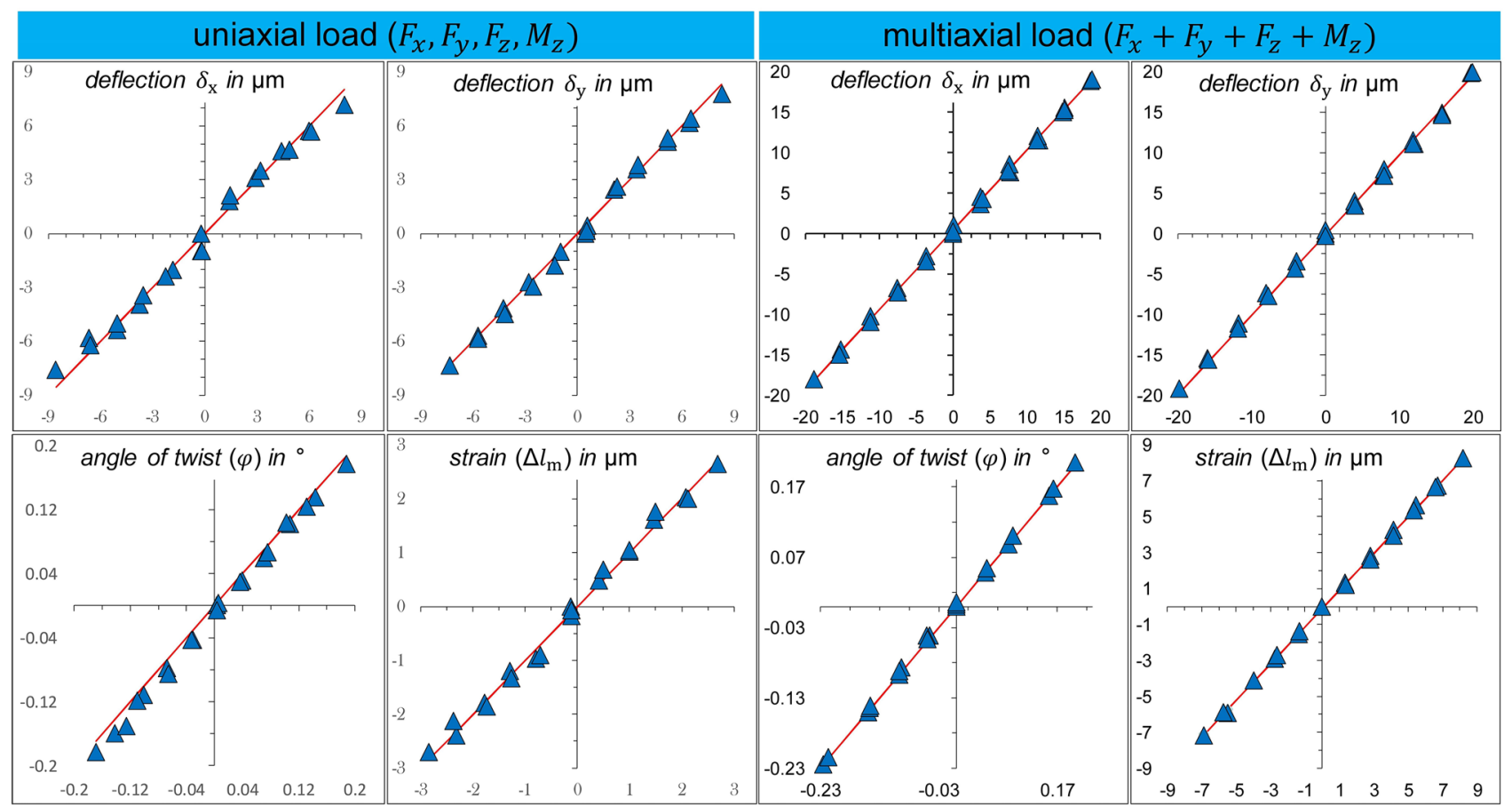

Fig. 12 Results of uniaxial and multiaxial loading of a prototype with an integrated optical sensor. The vertical axis shows the value determined by the developed sensor, and the horizontal axis shows the reference values obtained by a commercial reference sensor according to [39] 


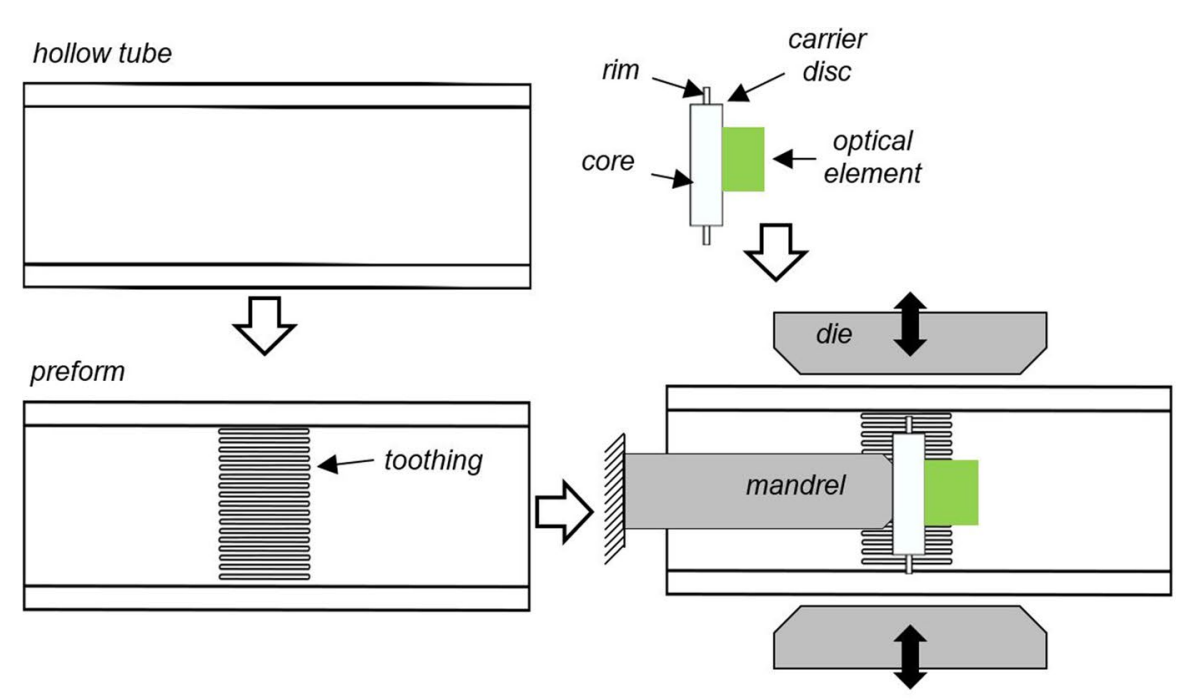

(a)

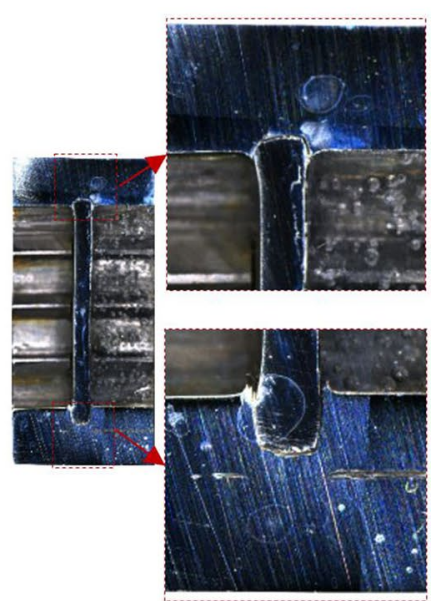

(b)

Fig. 13 a Process design for the positionally accurate integration of optical sensors into tubular structures, $\mathbf{b}$ integrated disc in an tube by rotary swaging

joining partners, which allow the joining zone to be created with low joining forces. When integrating carrier disks of optical elements in hollow tube, e.g. by rotary swaging, a possible design of the joining partners can be as follows: the carrier disk to be integrated consists of a stiff area (thick core), to which the sensitive optical elements are attached, and an easily deformable region (thin rim) to create the joining zone. The contact surface of the other joining partner (tube) can be modified into a slightly deformable area by means of internal toothing. Figure 13a illustrates this process concept.

Figure 13 shows the described process design for achieving positionally accurate joining by recess rotary swaging. In the first tests, a thin-walled disk $(1 \mathrm{~mm}$, 1.2379 steel) was positionally fixed on a mandrel and then integrated into a pre-toothed tube $(\mathrm{D}=22 \mathrm{~mm}, \mathrm{t}=3 \mathrm{~mm}$, S355J2G3 steel) by recess rotary swaging. As a result, a successful form-fit and force-fit joining at almost no deflection of the disk was observed (Fig. 13b).

\section{Conclusion and comparison of the joining processes}

Numerous studies on sensor integration into load-bearing structures and machine elements demonstrate ongoing advances in the field of digitization. Sensory structures have been successfully manufactured using different manufacturing techniques. However, to meet the rising demand for sensory structures, higher flexibility in low-cost manufacturing of such structures is needed. In spite of its high flexibility, additive manufacturing is still not a suitable technology for the cost-effective mass production of sensory structures. On the other hand, the high temperatures associated with casting, welding or brazing imposes significant restrictions on possible sensors to be integrated on thermal high isolated elementary sensors, such as the thick film strain gauge sensor covered with protective layers or the specially coated fiber glass sensors. This represents a major limitation, especially concerning the integration of sensor electronics. Coating with paint sensors and the integration of sensors on the surface of a structure by pressing is only applicable in some applications. Load-bearing structures and machine elements are usually exposed to harsh environments where they are affected by temperature, humidity, and mechanical loads already present.

Due of the ability to integrate functional sensors with the associated electronics without any thermal interference, joining by forming seems to be a particularly suitable technology. However, the generally strict design requirements for the interface between sensor and host structure pose an unavoidable challenge when manufacturing sensory structures with the capability of multi-axis force/torque measurement. The authors consider the optical measuring concept to be a very promising approach to extend the flexibility of the joining process of force/torque sensors, since the detectability of acting loads on the structures does not depend on the mechanical strength of the joint interface. However, replacing electromechanical sensors by optical measurement technology requires a significant step in the joining process: previously researched process designs for the force and form-lock joining of electromechanical sensors and 
host structures sought to control the pre-stress state within the sensor. The optical non-contact measurement concept, on the other hand, requires high positional accuracy during assembly and thus positional control during joining. This challenge will be addressed in a future study by the authors.

Acknowledgements This research is funded by the Deutsche Forschungsgemeinschaft (DFG, German Research Foundation)_-Project number 460244297. The authors would like to thank the German Research Foundation for founding and supporting this research project.

Funding Open Access funding enabled and organized by Projekt DEAL.

Open Access This article is licensed under a Creative Commons Attribution 4.0 International License, which permits use, sharing, adaptation, distribution and reproduction in any medium or format, as long as you give appropriate credit to the original author(s) and the source, provide a link to the Creative Commons licence, and indicate if changes were made. The images or other third party material in this article are included in the article's Creative Commons licence, unless indicated otherwise in a credit line to the material. If material is not included in the article's Creative Commons licence and your intended use is not permitted by statutory regulation or exceeds the permitted use, you will need to obtain permission directly from the copyright holder. To view a copy of this licence, visit http://creativecommons.org/licenses/by/4.0/.

\section{References}

1. Melz T, Wiedemann M, Melzer T (2016) Smarte Strukturen und Systeme Tagungsband des 4SMARTS-Symposiums, 6-7. April 2016, Darmstadt. De Gruyter Oldenbourg, Oldenbourg

2. Anderl R, Eigner M, Sendler U, Stark R (2012) Smart engineering: interdisziplinäre Produktentstehung. Springer, Berlin

3. ConSenses $\mathrm{GmbH}$ [Internet]

4. Kraus B, Neu M, Kirchner E (2020) Sensing machine elements as enablers of comprehensive digitization - a review. In: 2020 10th international electric drives production conference, EDPC 2020Proceedings, Institute of Electrical and Electronics Engineers Inc. https://doi.org/10.1109/EDPC51184.2020.9388181

5. Tränkler H-R (2014) Einführung in die Sensortechnik BT-Sensortechnik: Handbuch für Praxis und Wissenschaft. In: Tränkler H-R, Reindl L (eds) Springer, Berlin, pp 3-20. https://doi.org/10. 1007/978-3-642-29942-1_1

6. Mukherjee A, Panja AK, Dey N (2020) Introduction to sensors and systems. Begin Guide Data Agglom Intell Sens. https://doi. org/10.1016/B978-0-12-820341-5.00001-1

7. Bolton W (2015) Instrumentation system elements. Instrum Control Syst. https://doi.org/10.1016/B978-0-08-100613-9.00002-X

8. Groche P, Türk M (2011) Smart structures assembly through incremental forming. CIRP Ann Manuf Technol. https://doi.org/ 10.1016/j.cirp.2011.03.003

9. Mori KI, Bay N, Fratini L, Micari F, Tekkaya AE (2013) Joining by plastic deformation. CIRP Ann 62:673-694. https://doi.org/10. 1016/J.CIRP.2013.05.004

10. Shields J (1984) Adhesive bonding. Eng Des Guides. https://doi. org/10.1533/9781845690755

11. SCHULER GmbH (1998) Basic principles of metal forming. In: Metal forming handbook. Springer, Berlin, Heidelberg. https:// doi.org/10.1007/978-3-642-58857-0_2
12. Tiedemann R, Pille C, Dumstorff G, Lang W (2017) Sensor integration in castings made of aluminum - new approaches for direct sensor integration in aluminum high pressure die casting. Key Eng Mater. https://doi.org/10.4028/www.scientific.net/KEM.742.786

13. Schwankl M, Rübner M, Singer RF, Körner C (2013) Integration of PZT-ceramic modules using hybrid structures in high pressure die casting. Procedia Mater Sci 2:166-172. https://doi.org/ 10.1016/j.mspro.2013.02.020

14. Wong KV, Hernandez A (2012) A review of additive manufacturing. ISRN Mech Eng 2012:1-10. https://doi.org/10.5402/ 2012/208760

15. Hehr A, Norfolk M, Wenning J, Sheridan J, Leser P, Leser P et al (2021) Additive manufacturing of composites and complex materials integrating fiber optic strain sensors into metal using ultrasonic additive manufacturing. JOM. https://doi.org/ 10.1007/s11837-017-2709-8

16. Zou R, Cao R, Zaghloul MAS, Yan A, Chen R, Ohodnicki P et al. (2014) Optical fiber sensor-fused additive manufacturing and its applications in residual stress measurements in titanium parts. In: Optics InfoBase conference papers, Optical Society of America. p Th1A.7. https://doi.org/10.1364/APOS.2016. Th1A.7

17. Smith $P$ (2007) Chapter 6-fabrication, assembly, and erection. In: Smith PBT-TF of PD, editor. The fundamentals of piping design, pp 171-189. https://doi.org/10.1016/B978-1-93376204-3.50015-1

18. Grandal T, Fraga S, Vazquez JA, Zornoza A (2016) Technique for embedding fiber optics in metallic structures for smart material applications. In: 8th European workshop on structural health monitoring, EWSHM 2016

19. Grandal T, Zornoza A, Fraga S, Castro G, Sun T, Grattan KTV (2018) Laser cladding-based metallic embedding technique for fiber optic sensors. J Lightw Technol 36:1018-1025. https://doi. org/10.1109/JLT.2017.2748962

20. Sandlin S, Kosonen T, Hokkanen A, Heikinheimo L (2007) Use of brazing technique for manufacturing of high temperature fibre optical temperature and displacement transducer. Mater Sci Technol 23:1249-1255. https://doi.org/10.1179/17432 $8407 X 226662$

21. Cavillon M, Lancry M, Poumellec B, Wang Y, Canning J, Cook $\mathrm{K}$ et al (2019) Overview of high temperature fibre Bragg gratings and potential improvement using highly doped aluminosilicate glass optical fibres. J Phys Photonics. https://doi.org/10.1088/ 2515-7647/ab382f

22. Zhang Y (2006) In situ fatigue crack detection using piezoelectric paint sensor. J Intell Mater Syst Struct 17:843-852. https://doi.org/ 10.1177/1045389X06059957

23. Groche P, Wohletz S, Brenneis M, Pabst C, Resch F (2014) Joining by forming - a review on joint mechanisms, applications and future trends. J Mater Process Technol. https://doi.org/10.1016/j. jmatprotec.2013.12.022

24. Schubert A, Wittstock V, Koriath HJ, Jahn SF, Peter S, Müller B et al (2014) Smart metal sheets by direct functional integration of piezoceramic fibers in microformed structures. Microsyst Technol. https://doi.org/10.1007/s00542-013-1836-6

25. Schubert A, Wittstock V, Jahn SF, Müller B, Müller M (2014) Joining by forming of piezoceramic macro-fiber arrays within micro-structured surfaces of aluminum sheets. Prod Eng Res Dev. https://doi.org/10.1007/s11740-013-0498-7

26. Müller B, Pierer A, Schmidt M, Schubert A, Koriath HJ, Putz $M$ et al (2017) In-process monitoring of joining operations for piezoceramic elements. Key Eng Mater. https://doi.org/10.4028/ www.scientific.net/kem.742.800

27. Groche P, Fritsche D, Tekkaya EA, Allwood JM, Hirt G, Neugebauer R (2007) Incremental bulk metal forming. CIRP Ann Manuf Technol. https://doi.org/10.1016/j.cirp.2007.10.006 
28. Groche P, Krech M (2017) Efficient production of sensory machine elements by a two-stage rotary swaging process-relevant phenomena and numerical modelling. J Mater Process Technol. https://doi.org/10.1016/j.jmatprotec.2016.11.034

29. Groche P, Brenneis M (2014) Manufacturing and use of novel sensoric fasteners for monitoring forming processes. Measurement. https://doi.org/10.1016/j.measurement.2014.03.042

30. Krech M, Trunk A, Groche P (2018) Controlling the sensor properties of smart structures produced by metal forming. J Mater Process Technol. https://doi.org/10.1016/j.jmatprotec.2018.07.014

31. Al-Baradoni N, Krech M, Groche P (2021) In-process calibration of smart structures produced by incremental forming. Prod Eng Res Dev 15:79-87. https://doi.org/10.1007/s11740-020-01002-6

32. Drossel W-G, Hensel S, Nestler M, Müller R (2018) Method for large-scale production of piezoceramic-metal-compounds. Adv Eng Mater 20:1800430. https://doi.org/10.1002/ADEM.20180 0430

33. Drossel W-G, Nestler M, Hensel S (2019) Development of steps in an automated process chain for piezoceramic-metal compound production. J Manuf Mater Process 3:3. https://doi.org/10.3390/ JMMP3010003

34. Kräusel V, Graf A, Heinrich M, Decker R, Caspar M, Kroll L et al (2015) Development of hybrid assembled composites with sensory function. CIRP Ann Manuf Technol 64:25-28. https:// doi.org/10.1016/j.cirp.2015.04.054

35. Krech M (2020) Adaptive forming process for the production and simultaneous calibration of metallic structures with componentintegrated force and torque sensors. Adaptiver Umformprozess zur Herstellung und simultanen Kalibrierung von metallischen Strukturen mit bauteil. Shaker Verlag, Düren

36. Kang MK, Lee S, Kim JH (2014) Shape optimization of a mechanically decoupled six-axis force/torque sensor. Sens Actuators A Phys 209:41-51. https://doi.org/10.1016/j.sna.2014.01.001

37. Lin CY, Ahmad AR, Kebede GA (2020) Novel mechanically fully decoupled six-axis force-moment sensor. Sensors (Switzerland) 20:395. https://doi.org/10.3390/s20020395

38. Hu S, Wang H, Wang Y, Liu Z (2018) Design of a novel six-axis wrist force sensor. Sensors (Switzerland) 18:3120. https://doi.org/ $10.3390 / \mathrm{s} 18093120$

39. Al-Baradoni N, Groche P (2021) Sensor integrated load-bearing structures: measuring axis extension with DIC-based transducers. Sensors (Switzerland) 21:4104. https://doi.org/10.3390/s2112 4104

40. Müller M, Müller B, Hensel S, Nestler M, Jahn SF, Müller R et al (2016) Structural integration of piezoceramic fibers in deep drawn sheet metal for material-integrated health monitoring. Mechatronics 34:100-110. https://doi.org/10.1016/J.MECHATRONICS. 2015.09.006

Publisher's Note Springer Nature remains neutral with regard to jurisdictional claims in published maps and institutional affiliations. 